Article

\title{
Electrochemical Enzyme Biosensor Bearing Biochar Nanoparticle as Signal Enhancer for Bisphenol A Detection in Water
}

\author{
Yang Liu, Lan Yao, Lingzhi He, Na Liu and Yunxian Piao * \\ Key Laboratory of Groundwater Resources and Environment (Jilin University), Ministry of Education, \\ Jilin Provincial Key Laboratory of Water Resources and Environment, College of New Energy and Environment, \\ Jilin University, Changchun 130021, China; yangliu16@mails.jlu.edu.cn (Y.L.); yaolan17@mails.jlu.edu.cn (L.Y.); \\ helz17@mails.jlu.edu.cn (L.H.); liuna@jlu.edu.cn (N.L.) \\ * Correspondence: yxpiao@jlu.edu.cn; Tel.: +86-186-0441-4674; Fax: +86-431-8850-2606
}

Received: 22 February 2019; Accepted: 31 March 2019; Published: 4 April 2019

\begin{abstract}
An electrochemical tyrosinase enzyme (Tyr) biosensor using a highly conductive sugarcane derived biochar nanoparticle (BCNP) as a transducer and signal enhancer (BCNPs/Tyr/Nafion/GCE) was developed for the sensitive detection of bisphenol A (BPA). The BCNPs/Tyr/Nafion/GCE biosensor exhibited improved amperometric current responses such as higher sensing signal, decreased impedance and lowered reduction potential compared with the Tyr/Nafion/GCE due to high conductivity property of the biochar nanoparticle. Under the optimized conditions, it could detect BPA in good sensitivity with linear range from 0.02 to $10 \mu \mathrm{M}$, and a lowest detection limit of $3.18 \mathrm{nM}$. Moreover, it showed a low $K_{\mathrm{m}}$ value, high reproducibility and good selectivity over other reagents, and the BCNPs/Tyr complex solution also showed good stability with $86.9 \%$ of sensing signal maintained after one month storage. The biosensor was also successfully utilized for real water detection with high accuracy as validated by high performance liquid chromatography. Therefore, the biochar nanoparticle based enzyme biosensor proved to be a potential and reliable method for high performance detection of pollutants in the environment.
\end{abstract}

Keywords: biochar nanoparticle; enzyme; bisphenol A; biosensor

\section{Introduction}

Bisphenol A (2, 2-bis(4-hydroxyphenyl)propane, BPA) is a phenolic compound with high production volume widely used in the plastic industry, in particular as a monomer for producing polycarbonate plastics (PC) and epoxy resins [1-3]. It is also an endocrine disrupting compound, has estrogenic activity, and may have adverse effects on humans, wildlife, and reproductive systems [4]. BPA has been detected in many areas, such as freshwater, seawater, landfill, sludges, air, dust particles [5,6], and even in food matrices and drinking water [7,8]. The predicted no-effect concentration of BPA on the scale of around several micrograms per liter $[9,10]$. Therefore, it is necessary to develop a sensitive, reliable and simple method to detect BPA.

A variety of analysis methods for BPA detection have been used, such as liquid chromatography-mass spectrometry [11], liquid chromatography-tandem mass spectrometry [12], gas chromatography-mass spectrometry [11,13], liquid chromatography-coulometric detection [14], liquid chromatography-fluorescence detection [15,16] and liquid chromatography-UV detection [17]. These methods have high sensitivity and reliability, however, most of them are time consuming, cannot be performed on-site and require professional and technical personnel. To overcome these problems, a series of new methods have emerged including the fluorometric method [18,19], enzyme linked immunosorbent assays [20] and so on. Among these, the electrochemical methods [21], 
electrochemical enzyme biosensors in particular have drawn great attention due to their simplicity, sensitivity, selectivity, low cost, and field measurement capabilities.

It is well known that sensing materials play an extremely important role in the preparation of enzyme biosensors. They are the core of enzyme biosensors because they not only improve the catalytic activity and stability of the enzyme, but also enhance the sensitivity of the biosensors. As a new material, biochar has gained very much attention in this capacity. Biochar is the carbon-rich material usually obtained through the heating of biomass, such as wood, manure or leaves in a closed container with little or no available air [22]. There are some essential advantages of biochar, such as high surface area due to the unique porous structure, high cost effectiveness, sustainability, and an easy production process which allows the production of materials with extensive applications at a lower cost compared to materials from petrochemical or other chemical processes [23]. Furthermore, the source of biochar is ubiquitous, and plant derived biochar may provide a biocompatible environment for the stable accommodation of biomaterials such as microorganisms and enzymes [24]. For years, biochar was mainly used as a contaminant adsorbent, and also used in soil amendment to mitigate greenhouse gas emissions and improve soil quality. Recently, it was also utilized as a precursor for making catalysts, and electrode materials in microbial fuel cells and sensors [23,25-33]. However, the utilization of highly conductive biochar derived nanoparticles for the construction of electrochemical enzyme biosensors has not yet been extensively studied.

Recently, we demonstrated some attractive characteristics of biochar that are beneficial for biochar based electrochemical sensor development. These include that nanometer-sized biochar particles denoted as biochar nanoparticles (BCNPs) have the greater surface area vs. the conventional millimeter sized biochar particles [34] and that biochars prepared at high pyrolysis temperature have a great electrochemical catalytic property [35-37]. In this sense, an enzyme biosensor prepared by using such biochar nanoparticles with outstanding electrochemical catalytic properties and high surface area would have the potential to improve detection sensitivity.

In this study, a tyrosinase enzyme biosensor with conductive biochar nanoparticles was constructed for bisphenol A determination in water. Tyrosinase as an ortho-hydroxylation oxidase was used as the signaling enzyme because it possesses catalytic bioactivity for BPA that can be oxidized sequentially to polyhydric phenol and the electrochemically active o-quinone [38-40], where the o-quinone further can be reduced at the electrode surface producing reducing current signal proportional to concentrations of BPA. The sensitivity, kinetic parameters, reproducibility and selectivity of the novel BCNP enzyme biosensor were explored. The applicability of the biosensor for real environmental detection was also well demonstrated using groundwater. Because of the great electrochemical properties of BCNP and the high catalytic activity of the loaded enzyme, sensitive and rapid detection of BPA pollutant would be enabled.

\section{Materials and Methods}

\subsection{Chemicals and Apparatus}

Bisphenol A (BPA), $\mathrm{K}_{3} \mathrm{Fe}(\mathrm{CN})_{6}$, a Nafion solution $(\sim 5 \%$ in a mixture of lower aliphatic alcohols and water) and absolute ethanol were purchased from Sigma Aldrich (St. Louis, MO, USA). Tyrosinase

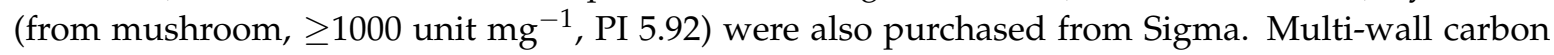
nanotubes abbreviated as MWNTs (diameter $<8 \mathrm{~nm}$; purity $>95 \%$; length, $10-30 \mu \mathrm{m}$ ) were obtained from the XFNANO. Graphite Nanopowder abbreviated as GN (average particle size $<100 \mathrm{~nm}$; purity $>95 \%$ ) were obtained from the SkySpring Nanomaterials, Inc. Graphene abbreviated as GP were obtained from the Shenzhen Turing Evolution Technology Co., Ltd, Shenzhen, China. All other reagents were analytical grade. A $50 \mathrm{mM}$ phosphate buffer solution (pH 7.0, $\mathrm{PB}$ ) consisting of $\mathrm{Na}_{2} \mathrm{HPO}_{4} \cdot 12 \mathrm{H}_{2} \mathrm{O}$ and $\mathrm{NaH}_{2} \mathrm{PO}_{4} \cdot 2 \mathrm{H}_{2} \mathrm{O}$ was used as electrolyte throughout the experiments unless addressed.

The scanning electron microscope images were obtained using a XL-30 field emission scanning electron microscope (FEI, Hillsboro, TX, USA). Fourier Transform Infrared (FTIR) spectra were obtained 
by using a Spectrum GX apparatus (Nicolet Company, Madison, WI, USA) with the medium infrared range (4000-1000 $\mathrm{cm}^{-1}$ ) and a spectral resolution of $4 \mathrm{~cm}^{-1}$. For FTIR analysis, the Tyr, BCNPs and $\mathrm{BCNPs} / \mathrm{Tyr}$ in double distilled water were dried at $30^{\circ} \mathrm{C}$ for about $3 \mathrm{~h}$, after which the dried samples were mixed with $\mathrm{KBr}$ powder, followed by the production of pellets with a tableting machine (FW-4, Tianguang Optical Instrument Co., Ltd., Tianjin, China). Circular dichroism (CD) spectroscopy was performed by a CD Spectropolarimeter (Jasco-810, Tokyo, Japan) at room temperature using a quartz cuvette with $1.0 \mathrm{~mm}$ path length in a wavelength range of $190-260 \mathrm{~nm}$. The specific surface areas of the materials were measured by the Brunauer-Emmett-Teller (BET) method (ASAP 2020).

\subsection{Preparation of Biochar Nanoparticles}

High conductivity biochar nanoparticles were prepared as previously reported [24]. Briefly, the dried bagasse was pyrolyzed at a temperature of $800{ }^{\circ} \mathrm{C}$ under the anoxic condition in a high temperature furnace (OTF-1200X, Kejing Material Technology Co., Ltd., Hefei, China). The obtained biochar was groud in an agate mortar to be finely adherent and dissolved in ultrapure water. After ultrasound sonication and centrifugation ( $5000 \mathrm{rpm}, 3 \mathrm{~min}$ ) processes, the centrifuged supernatant was filtered in a suction filtration device (filter pore size of $220 \mathrm{~nm}$ ), and the obtained biochar nanoparticles on the filter were dried for further use.

\subsection{Preparation of BCNP Enzyme Biosensor}

A glassy carbon electrode (GCE) with a $3 \mathrm{~mm}$ diameter (Shanghai Chenhua Instrument Co. Ltd., Shanghai, China) was polished with $0.5 \mu \mathrm{m}$ alumina slurry, and cleaned with absorbent cotton to remove excess alumina slurry. After sonication for $4 \mathrm{~min}$, it was washed with ultrapure water and methanol, and dried under a nitrogen gas. For the preparation of the BCNP enzyme biosensor, $0.5 \mathrm{mg} \mathrm{mL}^{-1}$ of tyrosinase was mixed with $0.375 \mathrm{mg} \mathrm{mL}^{-1}$ of BCNPs in the phosphate buffer solution ( $50 \mathrm{mM}, \mathrm{pH} 7.0)$. Then, the composite mixture $(5.4 \mu \mathrm{L})$ of BCNPs and enzyme was cast onto the pristine GCE electrode, followed by adding $0.6 \mu \mathrm{L}$ of Nafion $(0.5 \mathrm{wt} \%)$ (Scheme 1$)$. Then, it was dried under an ambient condition and denoted as BCNPs/Tyr/Nafion/GCE.

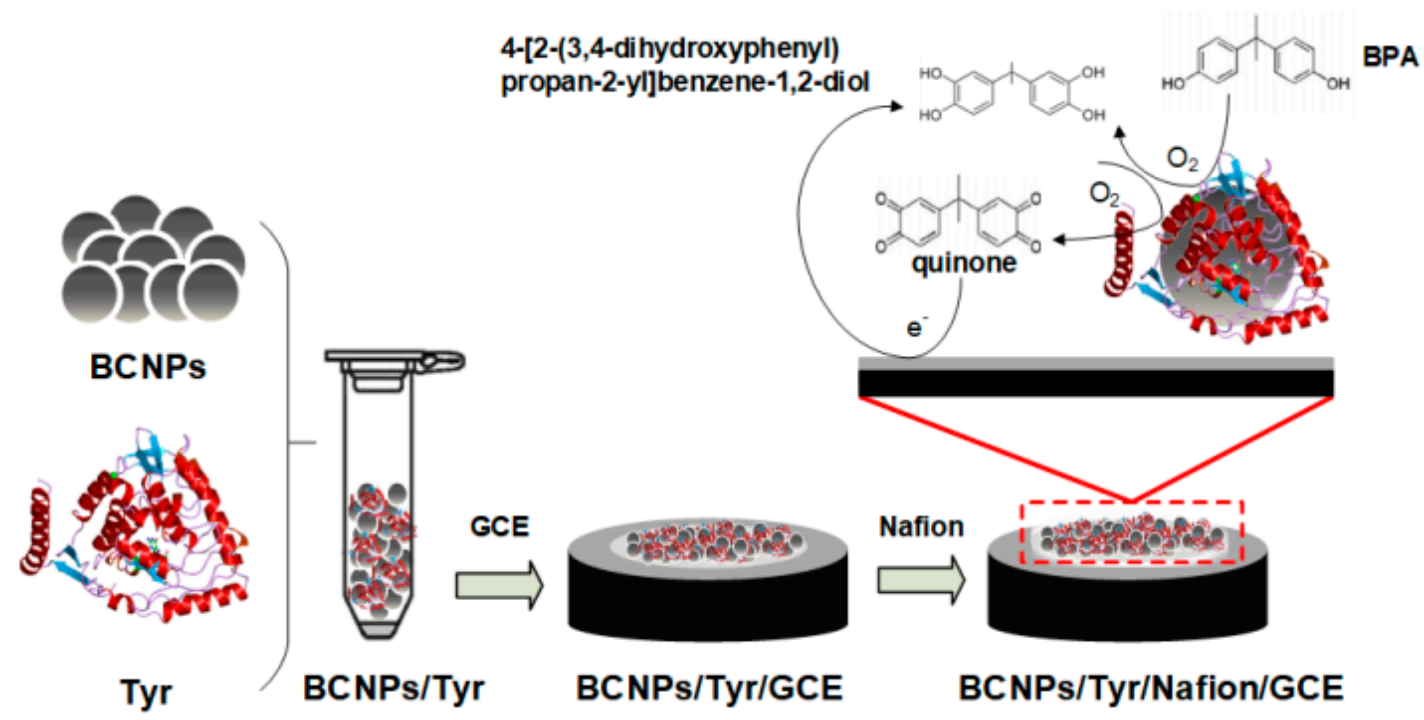

Scheme 1. Schematics of the procedures for the preparation of the BCNPs/Tyr/Nafion/GCE biosensor and the principle of electrochemical BPA sensing.

Other electrodes such as GN/Tyr/Nafion/GCE, MWNTs/Tyr/Nafion/GCE and GP/Tyr/Nafion/GCE were also prepared with GN, MWNTs and GP using the same procedures for preparation of the BCNPs/Tyr/Nafion/GCE. 


\subsection{Electrochemical Measurements}

Electrochemical measurements were performed using a CHI660E electrochemical workstation (Shanghai Chenhua Instrument Co. Ltd., Shanghai, China). A three-electrode system was used for electrochemical detection where the BCNPs/Tyr/Nafion/GCE electrode, $\mathrm{Ag} / \mathrm{AgCl}$ electrode, and platinum wire electrode were used as working, reference, and auxiliary electrodes, respectively. Electrochemical BPA detection was performed in a $10 \mathrm{~mL}$ PB solution. The cyclic voltammetry was performed at the potential range of -0.3 to $0.4 \mathrm{~V}$ with scan rate of $50 \mathrm{mV} \mathrm{s}^{-1}$. The electrochemical impedance spectroscopy (EIS) measurements were carried out in a $5 \mathrm{mM} \mathrm{K}_{3} \mathrm{Fe}(\mathrm{CN})_{6}$ solution containing $0.1 \mathrm{M} \mathrm{KCl}$ and the frequency range was from 0.01 to $100,000 \mathrm{~Hz}$.

\subsection{Real Environmental Water Sample Detection}

A ground water sample was obtained from the surrounding area of Jiefang Road, Chaoyang District, Changchun, China. Without any further treatment, the ground water sample was diluted 100-fold with PB solution and spiked with BPA to specific concentrations. The amounts of BPA were amperometrically analyzed by using the BCNPs/Tyr/Nafion/GCE biosensor.

The BPA concentration was also detected using the HPLC method with an LC-20AT HPLC system (Shimadzu, Kyoto, Japan) that was installed with a UV-vis detector at $278 \mathrm{~nm}$ and an Eclipse Plus C18 column $(4.6 \mathrm{~mm} \times 150 \mathrm{~mm}$, particle size of $5 \mu \mathrm{m}$, Agilent, Santa Clara, CA, USA). The mobile phase consisted of acetonitrile and ultrapure water at a volume ratio of 1:1, and the flow rate was set

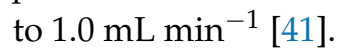

\section{Results and Discussion}

\subsection{Characterization of BCNP Enzyme Biosensor}

The as prepared BCNP have high conductivity and are well dispersible in solution, so they could be utilized for the BCNP based enzyme biosensor (BCNPs/Tyr/Nafion/GCE) construction by simply incorporation of Tyr as signaling enzyme (Scheme 1). The surface morphology of the prepared BCNPs/Tyr/Nafion/GCE electrode was evaluated with SEM analysis. As indicated in Figure 1, in comparison to the pristine GCE with smooth appearance surface (Figure 1A), the BCNPs modified GCE electrode presented biochar nanoparticles with an average particle size of $245.4 \mathrm{~nm}$ spreading all over the electrode surface (Figure 1B). For the BCNPs/Tyr/GCE electrode as shown in Figure 1C, the biochar nanoparticles on the electrode surface deteriorated due to presence of Tyr. After treating with Nafion, the surface of BCNPs/Tyr/Nafion/GCE electrode became smoother and more homogeneous (Figure 1D), suggesting well formation of BCNPs and enzyme film on the GCE.

The functional group properties of the prepared materials were evaluated by the Fourier Transform Infrared spectra. As shown in Figure 1E, the peak at $1637.1 \mathrm{~cm}^{-1}$ for acylamide I is the absorption of $-\mathrm{C}=\mathrm{O}$ stretching vibration of peptide linkages in the protein's backbone. The peak at $1523.1 \mathrm{~cm}^{-1}$ for acylamide II is corresponding to the absorption of $-\mathrm{N}-\mathrm{H}$ bending and $\mathrm{C}-\mathrm{N}$ stretching. These two peaks are characteristic peaks of Tyr that are commonly used to determine whether Tyr retains its native conformation. Comparing to the native Tyr, the BCNPs/Tyr presented the same characteristic peaks of Tyr, indicating that Tyr still maintains its original conformation in the BCNPs/Tyr complex. The secondary structure of Tyr in the BCNPs/Tyr complex was further evaluated by circular dichroism spectra. As shown in Figure 1F, both Tyr and BCNPs/Tyr showed two negative bands which represent the presence of $\alpha$-helix structures [42]. The bands of Tyr were located at about 212 and $224 \mathrm{~nm}$ while the characteristic bands of BCNPs/Tyr were presented approximately at 210 and $224 \mathrm{~nm}$. There was only a small difference in the characteristic band positions of the two samples. In addition, it was calculated that the $\alpha$-helix content in the Tyr sample was $27.5 \%$, and the $\alpha$-helix content in the BCNPs/Tyr was $25.0 \%$. The little changes in these two samples indicated that there was almost no conformational change in the BCNPs/Tyr complex for Tyr, and it also demonstrated the good biocompatibility and environmental friendliness of BCNP. 
(A)

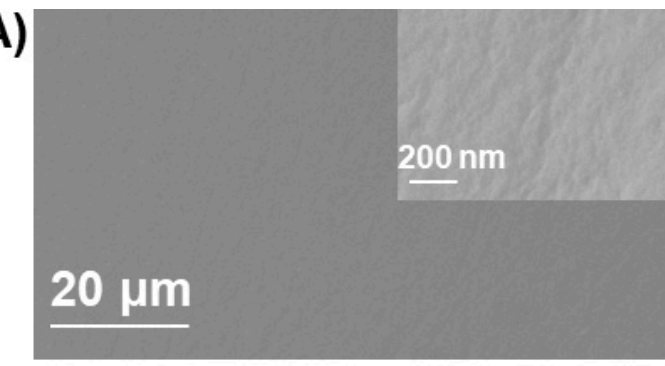

(C)

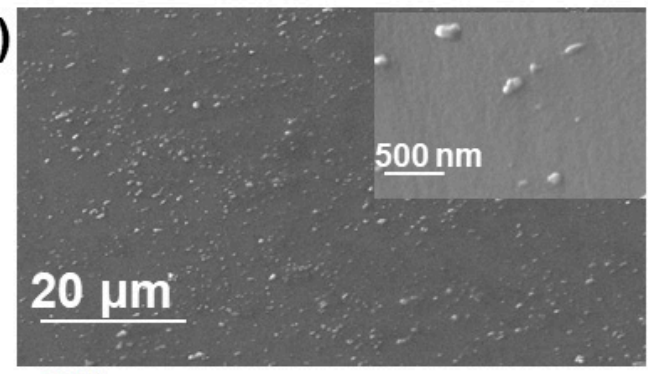

(E)

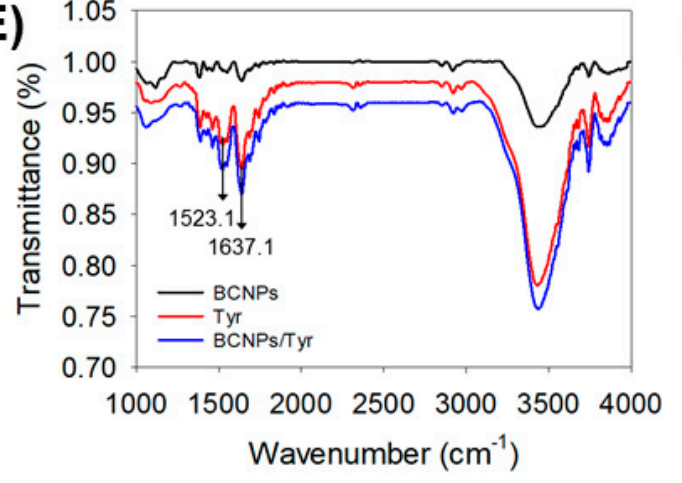

(B)

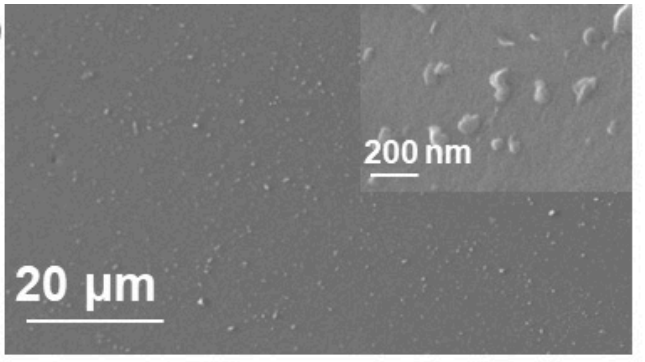

(D)

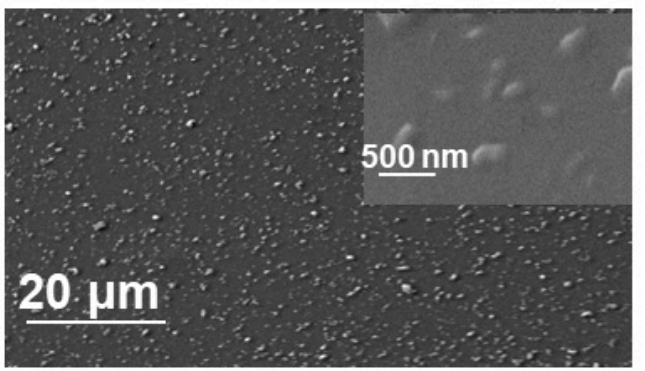

(F)

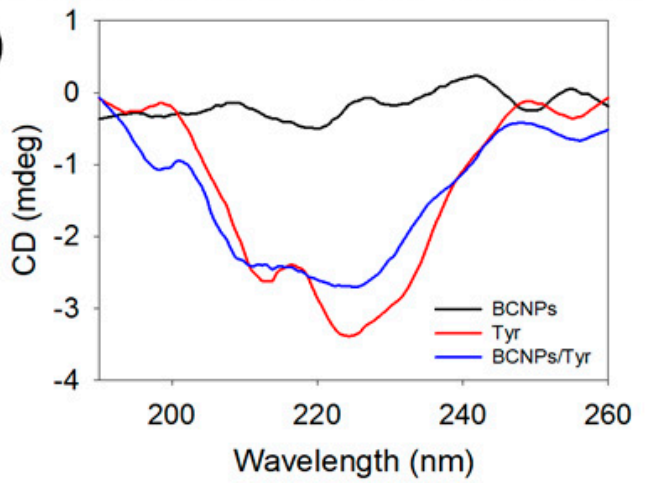

Figure 1. SEM images of (A) GCE, (B) BCNPs/GCE, (C) BCNPs/Tyr/GCE, (D) BCNPs/Tyr/Nafion/GCE. (E) FTIR spectra of BCNPs, Tyr and BCNPs/Tyr. (F) CD spectra of BCNPs, Tyr and BCNPs/Tyr.

\subsection{Electrochemical Impedance Analysis}

The electrochemical impedance measurements were utilized to detect the formation of each material on the GCE electrode and electron transfer properties of these electrodes. Figure 2 shows the electrochemical impedance spectroscopy (EIS) of a bare GCE, GCE modified with Nafion, BCNPs/Nafion/GCE, Tyr/Nafion/GCE and BCNPs/Tyr/Nafion/GCE in the $5 \mathrm{mM} \mathrm{K}{ }_{3} \mathrm{Fe}(\mathrm{CN})_{6}$ solution containing $0.1 \mathrm{M} \mathrm{KCl}$. As can be seen from the Figure 2, the impedance of bare GCE was $328.9 \Omega$. When the GCE was modified with Nafion, the Rct value was $0.0263 \Omega$, indicating that Nafion could both well protect the electrode material to keep it intact for a long time, and also was a good conductive film $[43,44]$. The Rct value at the BCNPs/Nafion/GCE electrode was $0.0169 \Omega$ which was smaller than that of the Nafion/GCE electrode, indicating that the BCNP have greater conductivity. When tyrosinase was immobilized on the surface of GCE, the Rct of Tyr/Nafion/GCE increased obviously to $2242 \Omega$ because of the increase of the thickness of the interface, which also proved that the introduction of tyrosinase effectively blocked the electron transfer between the electrode and $\left[\mathrm{Fe}(\mathrm{CN})_{6}\right] 3^{-} / 4^{-}[45]$. In addition, BCNPs/Tyr/Nafion/GCE electrode had a relatively small resistance value of $1483 \Omega$ in comparison, mainly due to the incorporation of the highly conductive BCNP. 


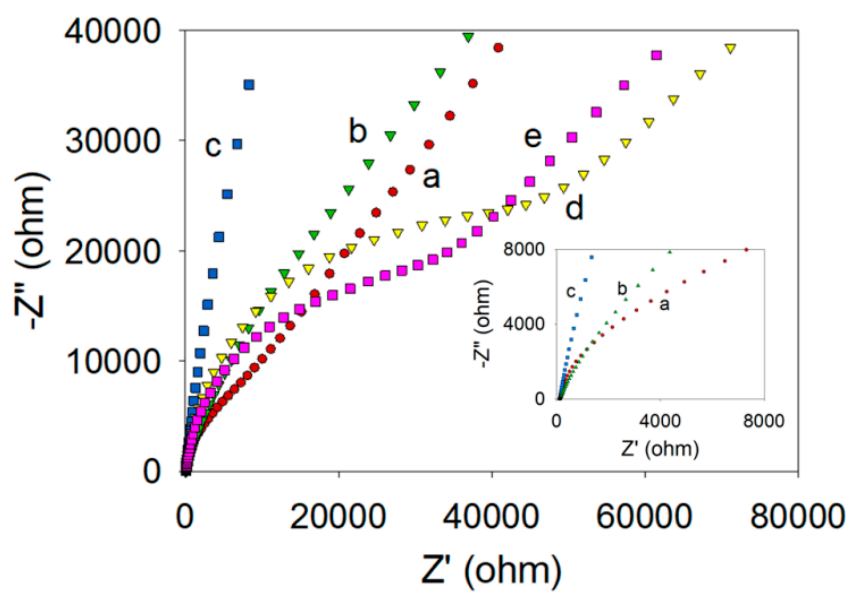

Figure 2. Nyquist plots of (a) GCE, (b) Nafion/GCE, (c) BCNPs/Nafion/GCE, (d) Tyr/Nafion/GCE, (e) BCNPs/Tyr/Nafion/GCE in $5 \mathrm{mM} \mathrm{K}_{3} \mathrm{Fe}(\mathrm{CN})_{6}$ containing $0.1 \mathrm{M} \mathrm{KCl}$.

\subsection{Electrochemical Response of BCNP Enzyme Biosensor to BPA}

The electrochemical response of BCNP enzyme biosensor to bisphenol A was investigated by the cyclic voltammetry method, since the immobilized Tyr enzyme can react with BPA and produces electrochemically active quinones that can be electrochemically reduced to corresponding polyhydric phenol and produce a cathodic current [40]. As shown in Figure 3, without target BPA, there was no current peak observed with the GCE (Figure 3a), BCNPs/Nafion/GCE (Figure 3b) and BCNPs/Tyr/Nafion/GCE (Figure 3c). It was observed that the BCNPs modified GCE presented higher current signal compared to the GCE due to the presence of BCNPs, and after involving Tyr enzyme, the current signal was a little reduced, attributed to the presence of non-conductive enzyme molecules, suggesting well maintenance of Tyr. When BPA $(100 \mu \mathrm{M})$ was added, a cathodic peak current at potential of $0.02 \mathrm{~V}$ was presented with the BCNPs/Tyr/Nafion/GCE, where the current change was $2.703 \mu \mathrm{A}$ (Figure 3d), suggesting successful generation of electrochemical current response of the immobilized Tyr in the BCNP biosensor with the presence of target BPA. By using the Tyr/Nafion/GCE sensor (Figure 3e), the BPA reduction peak current can also be observed, but with less current change $(1.771 \mu \mathrm{A})$ and at a higher potential of $0.06 \mathrm{~V}$. This demonstrated that an enzyme biosensor constructed with BCNP could improve the electrochemical signal for BPA detection and also with lower reduction potential, which was attributed to the high conductivity and large specific surface area of the prepared BCNP.

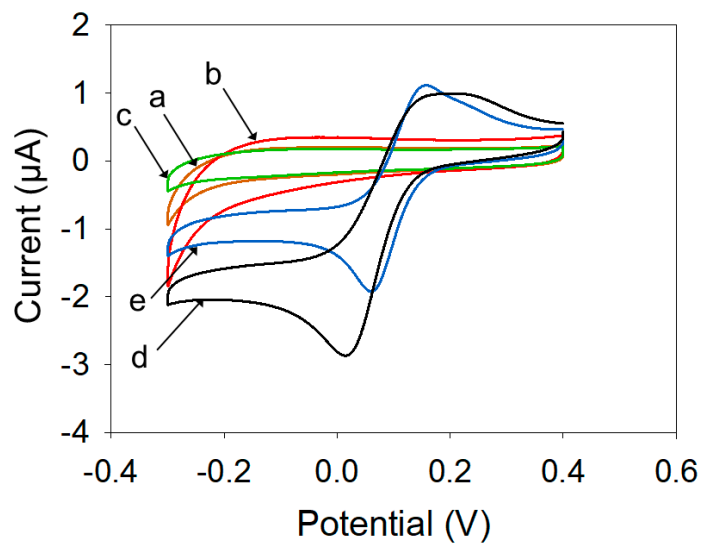

Figure 3. Cyclic voltammograms of the biosensor by using different electrodes (a-c) before and (d,e) after the addition of BPA $(100 \mu \mathrm{M})$, (a) GCE, (b) BCNPs/Nafion/GCE, (c) BCNPs/Tyr/ Nafion/GCE, (d) BCNPs/Tyr/Nafion/GCE, (e) Tyr/Nafion/GCE. Scan rate: $0.05 \mathrm{~V} \mathrm{~s}^{-1}$. 
Amperometric current properties of the BCNPs/Tyr/Nafion/GCE biosensor in response to BPA with different loading amounts of BCNP and Tyr were assessed in detail. As indicated in Figure 4A, with the increase of BCNP from 0.25 to $0.5 \mathrm{mg} \mathrm{mL}^{-1}$ (Tyr was $0.1 \mathrm{mg} \mathrm{mL}^{-1}$ ), the reduction current response of the BCNPs/Tyr/Nafion/GCE biosensor to BPA increased firstly and then decreased. When BCNP concentration was $0.375 \mathrm{mg} \mathrm{mL}^{-1}$, the current signal was the largest. The current profiles of BCNP biosensor with various amounts of Tyr loaded, in response to BPA, are indicated in Figure 4B. As shown, the reduction currents increased with the elevation of the Tyr concentrations from 0.1 to $0.5 \mathrm{mg} \mathrm{mL}^{-1}$, and decreased with higher level of Tyr (BCNP was $0.375 \mathrm{mg} \mathrm{mL}^{-1}$ ), meanwhile, the reduction potentials were correspondingly increased from 0.02 (with $0.1 \mathrm{mg} \mathrm{mL}^{-1}$ of Tyr) to $0.08 \mathrm{~V}$ (with $0.5 \mathrm{mg} \mathrm{mL}^{-1}$ of Tyr). The reason for these phenomena was that greater concentrations of BCNP or Tyr resulted in the thicker films of the electrode surface, which led to an increase of interfacial electron transfer resistance [46]. Therefore, BCNPs/Tyr/Nafion/GCE biosensor prepared with $0.375 \mathrm{mg} \mathrm{mL}^{-1}$ of BCNP and $0.5 \mathrm{mg} \mathrm{mL}^{-1}$ of Tyr were used in the following study.

(A)

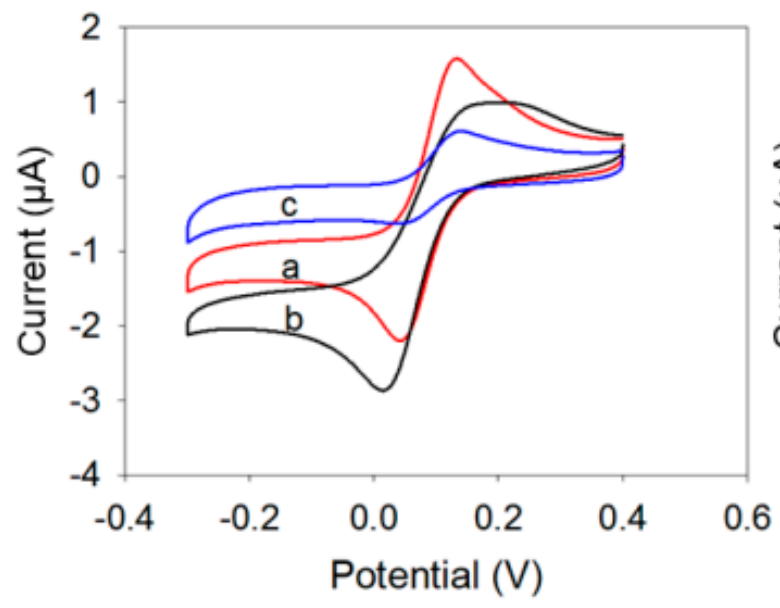

(B)

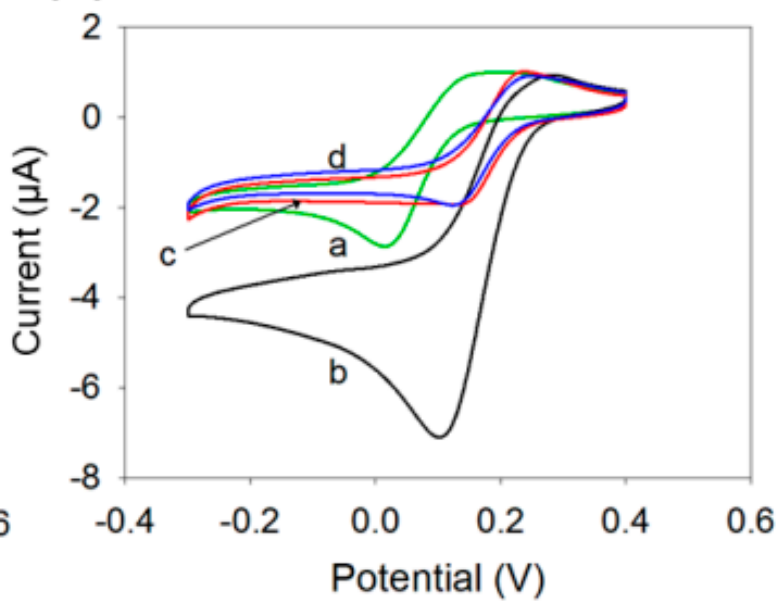

Figure 4. Cyclic voltammograms of the BCNPs/Tyr/Nafion/GCE biosensor in response to $100 \mu \mathrm{MBPA}$, (A) depending on various amounts of BCNP loading (a-c represent $0.25,0.375$ and $0.5 \mathrm{mg} \mathrm{mL}^{-1}$ of BCNP concentrations, respectively), and (B) depending on various amounts of Tyr loading (a-d represent 0.1, $0.5,1.0$ and $1.5 \mathrm{mg} \mathrm{mL}^{-1}$ of Tyr concentrations, respectively). Scan rate: $0.05 \mathrm{~V} \mathrm{~s}^{-1}$.

For comparison, other enzyme biosensors including GN/Tyr/Nafion/GCE, MWNTs/Tyr/ Nafion/GCE and GP/Tyr/Nafion/GCE that were prepared using graphite nanoparticle (GN), multi-wall carbon nanotube (MWNT) and graphene (GP), respectively, and their electrochemical properties were assessed. As shown in Figure S1A, electrochemical impedance spectroscopy indicated that the conductivity of the enzyme biosensor with BCNP was higher than enzyme biosensors prepared using GN and GP, and lower than with the MWNTs, i.e., MWNTs/Tyr/Nafion/GCE > BCNPs/Tyr/Nafion/GCE > GP/Tyr/Nafion/GCE > GN/Tyr/Nafion/GCE. From the amperometric current profiles in response to the same amounts of BPA in Figure S1B, it can be found that the enzyme biosensor with BCNP presented the largest current signal, where the order of the current change values was: BCNPs/Tyr/Nafion/GCE > GP/Tyr/Nafion/GCE > GN/Tyr/Nafion/GCE > MWNTs/Tyr/Nafion/GCE. One reason why the enzyme biosensor with BCNP presented the largest response signal to the same concentration of BPA is due to the good conductivity property of the proposed BCNP, and another possible factor is that the biocompatible characteristics of the plant derived biochar can make the biocatalytic property of the enzyme well maintained. In addition, the BCNP presented a larger surface area of $321.68 \mathrm{~m}^{2} \mathrm{~g}^{-1}$ than the graphite nanoparticle $\left(270.15 \mathrm{~m}^{2} \mathrm{~g}^{-1}\right)$, the graphene $\left(11.91 \mathrm{~m}^{2} \mathrm{~g}^{-1}\right)$ and the MWNTs $\left(247.80 \mathrm{~m}^{2} \mathrm{~g}^{-1}\right)$, that may have also contributed to improved current responses. 


\subsection{Sensitivity of BCNP Enzyme Biosensor}

In order to accurately and quantitatively detect BPA, the amperometry detection of BPA was performed with the optimized BCNPs/Tyr/Nafion/GCE biosensor (prepared with $0.375 \mathrm{mg} \mathrm{mL}^{-1}$ of BCNP and $0.5 \mathrm{mg} \mathrm{mL}^{-1}$ of Tyr). A typical amperometric I-t curve of BCNPs/Tyr/Nafion/GCE biosensor upon addition of specific amounts BPA solution to PB (50 mM, pH 7.0) with potential of $0.08 \mathrm{~V}$ (Figure S2) and under constant stirring was obtained. As can be seen from the Figure 5A, the reduction current of the BCNPs/Tyr/Nafion/GCE biosensor increased as the BPA concentration increased from 0.02 to $10 \mu \mathrm{M}$. The current values were linearly correlated with the BPA concentrations, with the linear regression equation of $I_{1}=0.0696 C+0.0003\left(R^{2}=0.9975\right)$ from 0.02 to $1 \mu \mathrm{M}$ of BPA and $I_{2}=0.0406 C+0.0502\left(R^{2}=0.9863\right)$ from 1 to $10 \mu \mathrm{M}$ of BPA for BCNPs/Tyr/Nafion/GCE (Figure 5B). In addition, the sensitivity of the BCNPs/Tyr/Nafion/GCE electrode was $0.985 \mu \mathrm{A} \mu \mathrm{M}^{-1} \mathrm{~cm}^{-2}$ when the BPA concentrations were $0.02-1 \mu \mathrm{M}$, and as BPA concentrations were $1-10 \mu \mathrm{M}$, the sensitivity of this electrode was $0.575 \mu \mathrm{A \mu} \mu \mathrm{M}^{-1} \mathrm{~cm}^{-2}$. The corresponding detection limit of the prepared BCNPs/Tyr/Nafion/GCE biosensor was $3.18 \mathrm{nM}$. Thus, these results fully proved that BCNP could improve the electrochemical biosensor detection performance, and this was mainly due to the excellent conductivity and good biocompatibility of BCNP. The analytical characteristics of the BCNPs/Tyr/Nafion/GCE biosensor are summarized in Table S1, in comparison with other sensors for bisphenol A detection reported in the literature. By comparison, it was further proved that the biosensor proposed in this study had great advantages.
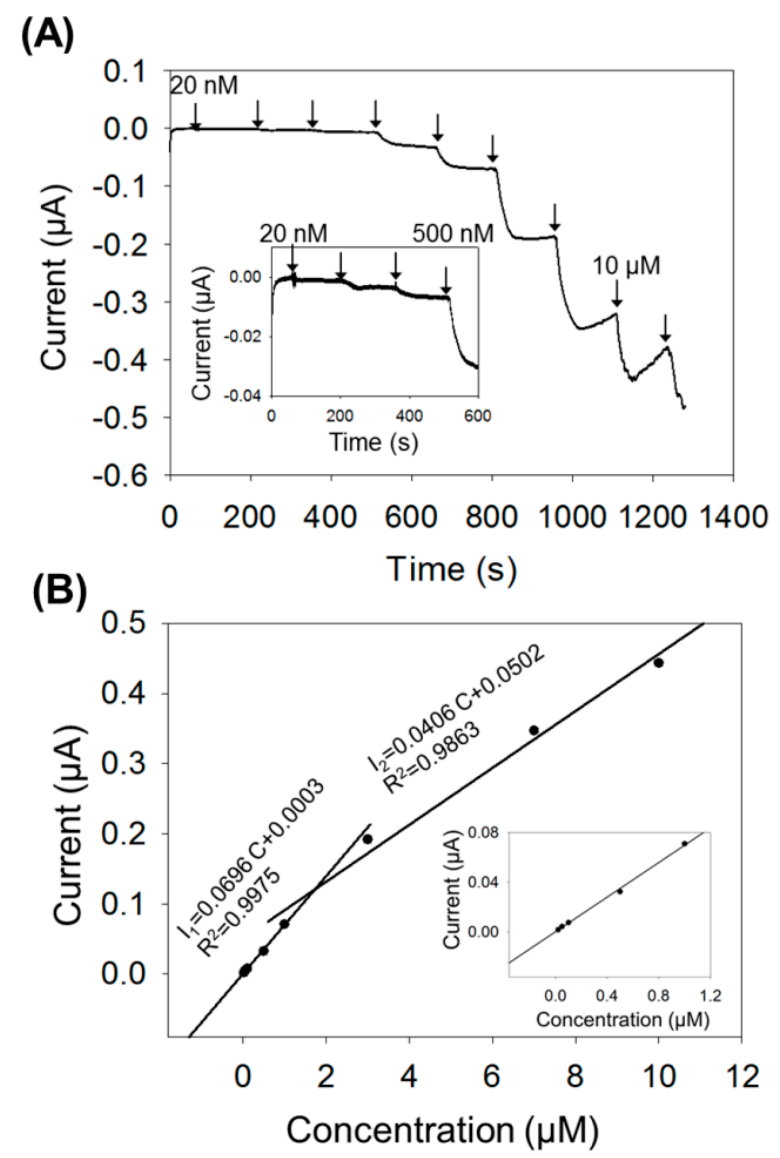

Figure 5. (A) Time-current responses of BCNPs/Tyr/Nafion/GCE biosensor for detecting various concentrations of BPA (BCNP $0.375 \mathrm{mg} \mathrm{mL}^{-1}$, Tyr $0.5 \mathrm{mg} \mathrm{mL}^{-1}$ ) in $10 \mathrm{~mL}$ PB solution at $0.08 \mathrm{~V}$. (Inset: Time-current responses of the BCNPs/Tyr/Nafion/GCE biosensor for detecting BPA at low concentrations.) (B) Calibration curve for BPA sensing by plotting the current values versus BPA concentration. The BPA concentrations are 20,50, 100 and $500 \mathrm{nM}$ and 1, 3, 7, 10 and $15 \mu \mathrm{M}$, respectively. 


\subsection{Kinetic Constant, Reproducibility, Stability and Selectivity}

The Michaelis-Menten constant $\left(K_{\mathrm{m}}\right)$ is the substrate concentration at which the enzymatic reaction rate is half of the maximum reaction rate, and it is also one of the most important kinetic parameters. In electrochemistry, the equation for measuring the Michaelis constant is $I_{\mathrm{ss}}^{-1}=1 / I_{\max }+K_{\mathrm{m}} /\left(I_{\max } C\right)$, where $I_{\mathrm{ss}}$ is the response current after addition of a certain concentration of substrate, $I_{\max }$ is the maximum current when the substrate is saturated and $C$ is the substrate concentration [47]. Kinetic parameter $K_{\mathrm{m}}$ was evaluated by the Lineweaver-Burk plot using BPA as substrate (Figure 6). When calculated, the $K_{\mathrm{m}}$ value was $1.13 \mu \mathrm{M}$, which was much smaller than the values reported in other literatures [48-50], indicating that the biosensor could maintain its good enzymatic activity, and also had a high affinity for BPA.

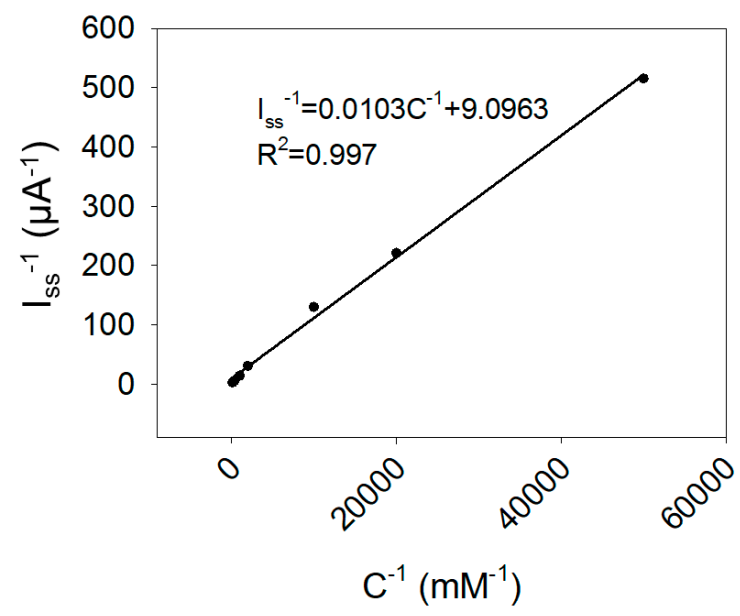

Figure 6. Lineweaver-Burk plots of the BCNPs/Tyr/Nafion/GCE electrode.

The reproducibility of the BCNPs/Tyr/Nafion/GCE biosensor was studied by determining the response to $3 \mu \mathrm{M}$ BPA by six different electrodes prepared independently. The RSD was found to be $7.28 \%$, demonstrating that the biosensor constructed in this paper had excellent reproducibility. Multiple cycle detection ability was also investigated, and found the proposed biosensor could perform four times repeated measurement of same amount of BPA with negligible signal lose (RSD of 5.74\%). Additionally, the storage stability of the BCNPs/Tyr complex solution was also further accessed by measuring amperometric response to $3 \mu \mathrm{M}$ BPA for every 7 days. During the measurement, the $\mathrm{BCNPs} /$ Tyr complex solution was stored at $4{ }^{\circ} \mathrm{C}$. This result showed that the current response of the electrode maintained $86.9 \%$ of its initial response after one month which indicated that the composite solution had good stability. This also means that in the actual testing, only the preparation of the electrode is required and there is no need to configure a fresh solution before preparing the electrode, which saves a lot of time and cost.

Selectivity of the biosensor toward $3 \mu \mathrm{M}$ BPA in the presence of various ionic interferents (with 100 -fold concentration higher than BPA) that may be present in water was assessed. As shown in Figure 7, with co-presence of the ions including $\mathrm{Cl}^{-}, \mathrm{SO}_{4}{ }^{2-}, \mathrm{Ca}^{2+}, \mathrm{Mg}^{2+}$, the BPA detection signals were not affected, suggested there is no interference. But, when there was $\mathrm{Cu}^{2+}$, the current signal response to BPA was increased for $11.10 \%$ compared to the control, this is because $\mathrm{Cu}^{2+}$ can promote the enzyme reaction as reported previously [51]. The BPA detection signals in the presence of other phenolic compounds were also evaluated. As indicated, both 2-chlorophenol and diphenolic acid would slightly increase the current signal (18.31\% and $17.76 \%$ increase), that is because tyrosinase enzyme can also catalytically convert of the two phenolic compounds to electroactive products. It was also found that the anionic surfactant, sodium dodecyl sulfate, could reduce the current signal of BPA detection (46.26\% reduction) due to inhibition of enzyme activity by the sodium dodecyl sulfate [52]. 


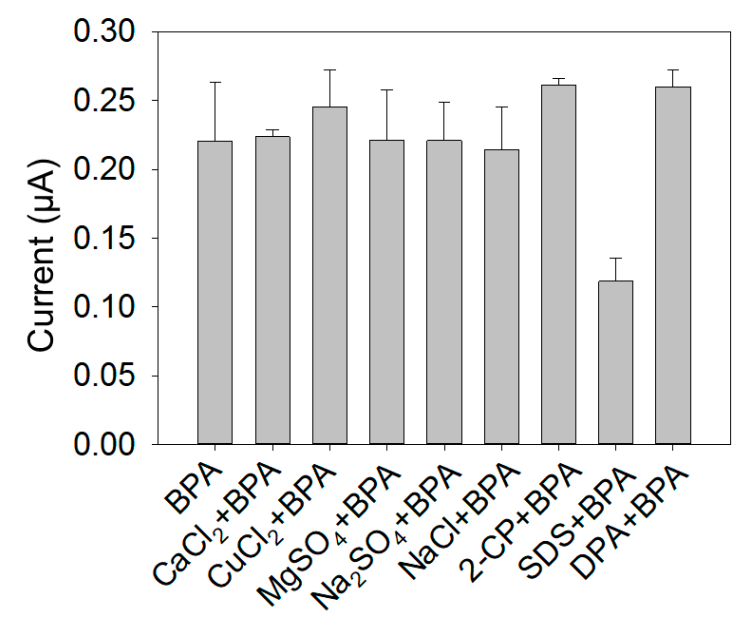

Figure 7. Specificity of the BCNPs/Tyr/Nafion/GCE biosensor for detection of BPA $(3 \mu \mathrm{M})$ in $50 \mathrm{mM}$ $\mathrm{PB}(\mathrm{PH}=7.0)$, where other irrelevant compounds coexist individually including $3 \mathrm{mM}$ of $\mathrm{CaCl}_{2}, \mathrm{CuCl}_{2}$, $\mathrm{MgSO}_{4}, \mathrm{Na}_{2} \mathrm{SO}_{4}, \mathrm{NaCl}, 2-\mathrm{CP}, \mathrm{SDS}$ and DPA.

\subsection{Real Sample Detection}

To verify the feasibility of the BCNPs/Tyr/Nafion/GCE biosensor constructed for real environmental water detection, the fresh groundwater samples were added to a concentration of BPA and then diluted 100-fold with PB for detection. Under optimal conditions, we quantified the concentrations of BPA in the treated water samples by amperometric I- $t$ curves. As can be seen in Table 1, the BCNPs/Tyr/Nafion/GCE biosensor electrochemical measurements of the treated water samples showed $96.67 \%, 108.60 \%$ and $106.14 \%$ recoveries with relative standard deviations of $2.14 \%$, $1.05 \%$ and $2.25 \%$. In addition, the accuracy of this biosensor was further verified by performing HPLC methods to detect the same concentration of BPA in groundwater. The recoveries of treated water samples measured by HPLC method were $96.67 \%, 119.20 \%$ and $99.57 \%$ for 3,5 and $7 \mu \mathrm{M}$ BPA, which indicated that the BCNPs/Tyr/Nafion/GCE biosensor electrochemical measurements were in good agreement with high-precision HPLC measurements. The results of the above analysis indicate that the BCNPs/Tyr/Nafion/GCE biosensor prepared in this article has great potential for the detection of actual water samples due to its high sensitivity, fast response time, low resistance, low cost, simple operation and ability to measure on site.

Table 1. Determination of BPA in real ground water samples using BCNPs/Tyr/Nafion/GCE biosensor and HPLC method.

\begin{tabular}{cccccc}
\hline \multirow{2}{*}{ Added $(\mu \mathrm{M})$} & \multicolumn{2}{c}{ Determined by BCNPs/Tyr/Nafion Electrochemical Biosensor } & \multicolumn{2}{c}{ Determined by HPLC } \\
\cline { 2 - 6 } & ${\text { Detected }(\mu \mathrm{M})^{\mathbf{a}}}^{\mathbf{a}}$ & RSD (\%) & Recovery (\%) & ${\text { Detected }(\boldsymbol{\mu M})^{\mathbf{a}}}^{\text {Recovery }(\%)}$ \\
\hline $\mathbf{3}$ & 2.90 & 2.14 & 96.67 & 2.90 & 96.67 \\
$\mathbf{5}$ & 5.43 & 1.05 & 108.60 & 5.96 & 119.20 \\
$\mathbf{7}$ & 7.43 & 2.25 & 106.14 & 6.97 & 99.57 \\
\hline
\end{tabular}

${ }^{\mathrm{a}}$ Mean of three measurements.

\section{Conclusions}

In this article, we used a Nafion embedding method to prepare a novel biochar nanoparticle-based tyrosinase biosensor for the detection of bisphenol A. This was the first time that biochar had been proposed for use in conjunction with enzymes in the biosensor. The prepared biochar nanoparticles had large specific surface areas, good conductivity, biocompatibility and environmental friendliness which were beneficial to enhance the activity of the enzyme. More importantly, the prepared BCNPs/Tyr/Nafion/GCE biosensor had high sensitivity, reproducibility, selectivity, a low $K_{\mathrm{m}}$ value, and also proved its successful application in real environmental water detection. Therefore, owning to 
the easy preparation of electrodes, simple system operation, and superior detection performances, the BCNP based enzyme biosensor would have great prospective for application in sensing.

Supplementary Materials: Supplementary Materials can be found at http:/ / www.mdpi.com/1424-8220/19/7/ 1619/s1.

Author Contributions: Y.P. and Y.L. conceived and designed the experiments, Y.L. performed the experiments, Y.P. and Y.L. analyzed the data and wrote the paper, L.Y., L.H. and N.L. participated in a full and extensive discussion, Y.P. supervised the entire project.

Funding: This work was financially supported by the National Natural Science Foundation of China (51809111) and the Natural Science Foundation from the Department of Science and Technology of Jilin Province of China (20150101094JC).

Acknowledgments: Thanks to Song Gao and the Key Laboratory of Groundwater Resources and Environment of the Ministry of Education of Jilin University for providing the instrumental and technical support for the high performance liquid chromatography analysis.

Conflicts of Interest: The authors declare no conflict of interest.

\section{References}

1. Lakind, J.S.; Naiman, D.Q. Daily intake of bisphenol A and potential sources of exposure: 2005-2006 National Health and Nutrition Examination Survey. J. Expo. Sci. Environ. Epidemiol. 2011, 21, 272-279. [CrossRef]

2. Howdeshell, K.L.; Peterman, P.H.; Judy, B.M.; Taylor, J.A.; Orazio, C.E.; Ruhlen, R.L.; Vom Saal, F.S.; Welshons, W.V. Bisphenol A is released from used polycarbonate animal cages into water at room temperature. Environ. Health Perspect. 2003, 111, 1180-1187. [CrossRef] [PubMed]

3. Dark, W.A.; Conrad, E.C.; Crossman, L.W., Jr. Liquid chromatographic analysis of epoxy resins. J. Chromatogr. A 1974, 91, 247-260. [CrossRef]

4. Segner, H.; Caroll, K.; Fenske, M.; Janssen, C.R.; Maack, G.; Pascoe, D.; Schafers, C.; Vandenbergh, G.F.; Watts, M.; Wenzel, A. Identification of endocrine-disrupting effects in aquatic vertebrates and invertebrates: Report from the European IDEA project. Ecotoxicol. Environ. Saf. 2003, 54, 302-314. [CrossRef]

5. Kang, J.H.; Kondo, F. Bisphenol A degradation in seawater is different from that in river water. Chemosphere 2005, 60, 1288-1292. [CrossRef] [PubMed]

6. Dorn, P.B.; Chou, C.S.; Gentempo, J.J. Degradation of bisphenol A in natural waters. Chemosphere 1987, 16, 1501-1507. [CrossRef]

7. Bach, C.; Dauchy, X.; Chagnon, M.C.; Etienne, S. Chemical compounds and toxicological assessments of drinking water stored in polyethylene terephthalate (PET) bottles: A source of controversy reviewed. Water Res. 2012, 46, 571-583. [CrossRef] [PubMed]

8. Alkasir, R.S.; Ganesana, M.; Won, Y.H.; Stanciu, L.; Andreescu, S. Enzyme functionalized nanoparticles for electrochemical biosensors: A comparative study with applications for the detection of bisphenol A. Biosens. Bioelectron. 2010, 26, 43-49. [CrossRef] [PubMed]

9. Li, Y.; Wang, L.; Liu, Y.; Huang, W.; Wu, L. The research progress of Bisphenol A's determination method. J. Anhui Agric. Sci. 2016, 44, 106-108.

10. Aschberger, K.; Munn, S.; Olsson, H.; Pakalin, S.; Pellegrini, G.; Vegro, S.; Paya Perez, A.B. Updated European Risk Assessment Repor 4,4'-Isopropylidenediphenol (Bisphenol-A); European Union Risk Assessment Report; EU Publications: Brussels, Belgium, 2008; pp. 114-115.

11. Gallart-Ayala, H.; Moyano, E.; Galceran, M.T. Recent advances in mass spectrometry analysis of phenolic endocrine disruptors and related compounds. Mass Spectrum. Rev. 2010, 29, 776-805. [CrossRef]

12. Gallart-Ayala, H.; Moyano, E.; Galceran, M.T. Analysis of bisphenols in soft drinks by on-line solid phase extraction fast liquid chromatography-tandem mass spectrometry. Anal. Chim. Acta 2011, 683, 227-233. [CrossRef] [PubMed]

13. Gatidou, G.; Thomaidis, N.S.; Stasinakis, A.S.; Lekkas, T.D. Simultaneous determination of the endocrine disrupting compounds nonylphenol, nonylphenol ethoxylates, triclosan and bisphenol A in wastewater and sewage sludge by gas chromatography-mass spectrometry. J. Chromatogr. A 2007, 1138, 32-41. [CrossRef] [PubMed]

14. Ouchi, K.; Watanabe, S. Measurement of bisphenol A in human urine using liquid chromatography with multi-channel coulometric electrochemical detection. J. Chromatogr. B 2002, 780, 365-370. [CrossRef] 
15. Wen, Y.; Zhou, B.S.; Xu, Y.; Jin, S.W.; Feng, Y.Q. Analysis of estrogens in environmental waters using polymer monolith in-polyether ether ketone tube solid-phase microextraction combined with high-performance liquid chromatography. J. Chromatogr. A 2006, 1133, 21-28. [CrossRef] [PubMed]

16. Cirillo, T.; Latini, G.; Castaldi, M.A.; Dipaola, L.; Fasano, E.; Esposito, F.; Scognamiglio, G.; Francesco, F.D.; Cobellis, L. Exposure to di-2-ethylhexyl phthalate, di-n-butyl phthalate and bisphenol A through infant formulas. J. Agric. Food Chem. 2015, 63, 3303-3310. [CrossRef] [PubMed]

17. Rezaee, M.; Yamini, Y.; Shariati, S.; Esrafili, A.; Shamsipur, M. Dispersive liquid-liquid microextraction combined with high-performance liquid chromatography-UV detection as a very simple, rapid and sensitive method for the determination of bisphenol A in water samples. J. Chromatogr. A 2009, 1216, 1511-1514. [CrossRef] [PubMed]

18. Fan, J.; Guo, H.; Liu, G.; Peng, P. Simple and sensitive fluorimetric method for determination of environmental hormone bisphenol A based on its inhibitory effect on the redox reaction between peroxyl radical and rhodamine 6G. Anal. Chim. Acta 2007, 585, 134-138. [CrossRef]

19. Duan, N.; Zhang, H.; Nie, Y.; Wu, S.; Miao, T.; Chen, J.; Wang, Z. Fluorescence resonance energy transfer-based aptamer biosensor for bisphenol A using lanthanide-doped $\mathrm{KGdF}_{4}$ nanoparticles. Anal. Methods 2015, 7, 5186-5192. [CrossRef]

20. Feng, Y.; Ning, B.; Su, P.; Wang, H.; Wang, C.; Chen, F.; Gao, Z. An immunoassay for bisphenol A based on direct hapten conjugation to the polystyrene surface of microtiter plates. Talanta 2009, 80, 803-808. [CrossRef]

21. Rahman, M.M.; Marwani, H.M.; Asiri, A.M.; Danish, E.Y. Detection of bisphenol A based on conducting binder supported hydrophobic 1,10-PhenanNTf 2 ionic liquid onto flat silver electrode by electrochemical approaches. Sens. Biosens. Res. 2015, 4, 70-77.

22. Harris, P. On charcoal. Interdiscip. Sci. Rev. 2013, 24, 301-306. [CrossRef]

23. Qian, K.; Kumar, A.; Zhang, H.; Bellmer, D.; Huhnke, R. Recent advances in utilization of biochar. Renew. Sustain. Energy Rev. 2015, 42, 1055-1064. [CrossRef]

24. Liao, N.; Li, Q.; Zhang, W.; Zhou, G.; Ma, L.; Min, W.; Ye, J.; Hou, Z. Effects of biochar on soil microbial community composition and activity in drip-irrigated desert soil. Eur. J. Soil Biol. 2016, 72, 27-34. [CrossRef]

25. Dong, X.; He, L.; Liu, Y.; Piao, Y. Preparation of highly conductive biochar nanoparticles for rapid and sensitive detection of $17 \beta$-estradiol in water. Electrochim. Acta 2018, 292, 55-62. [CrossRef]

26. De Oliveira, P.R.; Kalinke, C.; Gogola, J.L.; Mangrich, A.S.; Junior, L.H.M.; Bergamini, M.F. The use of activated biochar for development of a sensitive electrochemical sensor for determination of methyl parathion. J. Electroanal. Chem. 2017, 799, 602-608. [CrossRef]

27. Kalinke, C.; Oliveira, P.R.; Oliveira, G.A.; Mangrich, A.S.; Marcolino-Junior, L.H.; Bergamini, M.F. Activated biochar: Preparation, characterization and electroanalytical application in an alternative strategy of nickel determination. Anal. Chim. Acta 2017, 983, 103-111. [CrossRef]

28. Altuntaş, D.B.; Akgül, G.; Yanik, J.; Anik, Ü. A biochar-modified carbon paste electrode. Turk. J. Chem. 2017, 41, 455-465. [CrossRef]

29. Oliveira, P.R.; Kalinke, C.; Mangrich, A.S.; Marcolino-Junior, L.H.; Bergamini, M.F. Copper hexacyanoferrate nanoparticles supported on biochar for amperometric determination of isoniazid. Electrochim. Acta 2018, 285, 373-380. [CrossRef]

30. Xiang, Y.; Liu, H.; Yang, J.; Shi, Z.; Tan, Y.; Jin, J.; Wang, R.; Zhang, S.; Wang, J. Biochar decorated with gold nanoparticles for electrochemical sensing application. Electrochim. Acta 2018, 261, 464-473. [CrossRef]

31. Oliveira, P.R.D.; Lamy-Mendes, A.C.; Gogola, J.L.; Mangrich, A.S.; Marcolino Junior, L.H.; Bergamini, M.F. Mercury nanodroplets supported at biochar for electrochemical determination of zinc ions using a carbon paste electrode. Electrochim. Acta 2015, 151, 525-530. [CrossRef]

32. Agustini, D.; Mangrich, A.S.; Bergamini, M.F.; Marcolino-Junior, L.H. Sensitive voltammetric determination of lead released from ceramic dishes by using of bismuth nanostructures anchored on biochar. Talanta 2015, 142, 221-227. [CrossRef] [PubMed]

33. Gevaerd, A.; de Oliveira, P.R.; Mangrich, A.S.; Bergamini, M.F.; Marcolino-Junior, L.H. Evaluation of antimony microparticles supported on biochar for application in the voltammetric determination of paraquat. Mater. Sci. Eng. C 2016, 62, 123-129. [CrossRef] [PubMed]

34. Dong, X.; He, L.; Hu, H.; Liu, N.; Gao, S.; Piao, Y. Removal of $17 \beta$-estradiol by using highly adsorptive magnetic biochar nanoparticles from aqueous solution. Chem. Eng. J. 2018, 352, 371-379. [CrossRef] 
35. Chen, T.; Zhang, Y.; Wang, H.; Lu, W.; Zhou, Z.; Zhang, Y.; Ren, L. Influence of pyrolysis temperature on characteristics and heavy metal adsorptive performance of biochar derived from municipal sewage sludge. Bioresour. Technol. 2014, 164, 47-54. [CrossRef] [PubMed]

36. Ferreira, P.A.; Backes, R.; Martins, C.A.; de Carvalho, C.T.; da Silva, R.A.B. Biochar: A Low-cost Electrode Modifier for Electrocatalytic, Sensitive and Selective Detection of Similar Organic Compounds. Electroanalysis 2018, 30, 2233-2236. [CrossRef]

37. Kalinke, C.; Mangrich, A.S.; Marcolino-Junior, L.H.; Bergamini, M.F. Carbon Paste Electrode Modified with Biochar for Sensitive Electrochemical Determination of Paraquat. Electroanalysis 2016, 28, 764-769. [CrossRef]

38. Ragavan, K.V.; Rastogi, N.K.; Thakur, M.S. Sensors and biosensors for analysis of bisphenol-A. TrAC Trends Anal. Chem. 2013, 52, 248-260. [CrossRef]

39. Wu, L.; Deng, D.; Jin, J.; Lu, X.; Chen, J. Nanographene-based tyrosinase biosensor for rapid detection of bisphenol A. Biosens. Bioelectron. 2012, 35, 193-199. [CrossRef]

40. Kochana, J.; Wapiennik, K.; Kozak, J.; Knihnicki, P.; Pollap, A.; Wozniakiewicz, M.; Nowak, J.; Koscielniak, P. Tyrosinase-based biosensor for determination of bisphenol A in a flow-batch system. Talanta 2015, 144, 163-170. [CrossRef]

41. Dong, X.; Qi, X.; Liu, N.; Yang, Y.; Piao, Y. Direct Electrochemical Detection of Bisphenol A Using a Highly Conductive Graphite Nanoparticle Film Electrode. Sensors 2017, 17, 836. [CrossRef]

42. Wang, Y.; Zhang, G.; Wang, L. Interaction of prometryn to human serum albumin: Insights from spectroscopic and molecular docking studies. Pestic. Biochem. Phys. 2014, 108, 66-73. [CrossRef] [PubMed]

43. Yang, X.; Zhang, Y.; Hao, X.; Song, Y.; Liang, X.; Liu, F.; Liu, F.; Sun, P.; Gao, Y.; Yan, X.; et al. Nafion-based amperometric $\mathrm{H}_{2} \mathrm{~S}$ sensor using Pt-Rh/C sensing electrode. Sens. Actuators B Chem. 2018, 273, 635-641. [CrossRef]

44. Zhang, W.X.; Zheng, J.Z.; Shi, J.G.; Lin, Z.Q.; Huang, Q.T.; Zhang, H.Q.; Wei, C.; Chen, J.H.; Hua, S.R.; Hao, A.Y. Nafion covered core-shell structured $\mathrm{Fe}_{3} \mathrm{O}_{4} @$ graphene nanospheres modified electrode for highly selective detection of dopamine. Anal. Chim. Acta 2015, 853, 285-290. [CrossRef] [PubMed]

45. Kong, L.M.; Huang, S.S.; Yue, Z.L.; Peng, B.; Li, M.Y.; Zhang, J. Sensitive mediator-free tyrosinase biosensor for the determination of 2,4-dichlorophenol. Microchim. Acta 2009, 165, 203-209. [CrossRef]

46. Sanz, V.C.; Mena, M.L.; Gonzalez-Cortes, A.; Yanez-Sedeno, P.; Pingarron, J.M. Development of a tyrosinase biosensor based on gold nanoparticles-modified glassy carbon electrodes-Application to the measurement of a bioelectrochemical polyphenols index in wines. Anal. Chim. Acta 2005, 528, 1-8. [CrossRef]

47. Cai, C.X.; Chen, J. Direct electron transfer and bioelectrocatalysis of hemoglobin at a carbon nanotube electrode. Anal. Biochem. 2004, 325, 285-292. [CrossRef] [PubMed]

48. Campanha Vicentini, F.; Garcia, L.L.; Figueiredo-Filho, L.C.; Janegitz, B.C.; Fatibello-Filho, O. A biosensor based on gold nanoparticles, dihexadecylphosphate, and tyrosinase for the determination of catechol in natural water. Enzyme Microb. Technol. 2016, 84, 17-23. [CrossRef]

49. Wang, Y.; Zhai, F.; Hasebe, Y.; Jia, H.; Zhang, Z. A highly sensitive electrochemical biosensor for phenol derivatives using a graphene oxide-modified tyrosinase electrode. Bioelectrochemistry 2018, 122, 174-182. [CrossRef]

50. Sethuraman, V.; Muthuraja, P.; Anandha Raj, J.; Manisankar, P. A highly sensitive electrochemical biosensor for catechol using conducting polymer reduced graphene oxide-metal oxide enzyme modified electrode. Biosens. Bioelectron. 2016, 84, 112-119. [CrossRef]

51. Chen, T.; Xu, Y.; Peng, Z.; Li, A.; Liu, J. Simultaneous Enhancement of Bioactivity and Stability of Laccase by $\mathrm{Cu}^{2+} /$ PAA/PPEGA Matrix for Efficient Biosensing and Recyclable Decontamination of Pyrocatechol. Anal. Chem. 2017, 89, 2065-2072. [CrossRef]

52. Cserhati, T.; Forgacs, E.; Oros, G. Biological activity and environmental impact of anionic surfactants. Environ. Int. 2002, 28, 337-348. [CrossRef]

(C) 2019 by the authors. Licensee MDPI, Basel, Switzerland. This article is an open access article distributed under the terms and conditions of the Creative Commons Attribution (CC BY) license (http:/ / creativecommons.org/licenses/by/4.0/). 